\title{
Enhancing Communication Practices in Virtual New Product Development Projects
}

\author{
Päivi Lohikoski, Faculty of Technology, University of Oulu, Oulu, Finland \\ Jaakko Kujala, Faculty of Technology, University of Oulu, Oulu, Finland \\ Janne Härkönen, Faculty of Technology, University of Oulu, Oulu, Finland \\ Harri Haapasalo, Faculty of Technology, University of Oulu, Oulu, Finland \\ Matti Muhos, Micro-Entrepreneurship Research Group, University of Oulu, Oulu, Finland
}

\begin{abstract}
Virtual new product development (NPD) teams integrated via information and communication technology (ICT), can offer effective solutions to higher quality, service, customer responsiveness and individualized productization. Experts in NPD teams usually collaborate across the globe and across time zones by e-mail, tele-and web-conferencing, as well as other ICT, sometimes with inadequate language skills and with various ways of communicating and sharing information. Therefore, finding a shared understanding, relevant information, common language, and personal contacts across different sites may be challenging. The aim of this research was to study how communication practices are organized in virtual NPD. In addition to this, the scope was to study what kinds of competences are needed to enhance the efficiency of virtual communication in cross-cultural NPD. The authors conducted a multi-method case study of a global telecommunication company. The main findings were that members in virtual projects have different kinds of communication practices based on personal competences, habits, and preferences rather than company-level recommendations. The main contribution of this study is that virtual collaboration competences on a personal and organizational level play a significant role in enhancing efficiency in communication and when designing and utilizing communication practices. The authors'results may be used to support managerial decisions concerning practices of organizing global teams and when coordinating communication practices in complex global projects.
\end{abstract}

Keywords: Communication, New Product Development, Personal Virtual Collaboration Competence, Project Management, Virtual Collaboration Competence, Virtual Projects, Virtual Teams

\section{INTRODUCTION}

The importance of better understanding the functionalities of virtual organizations is increasing as more than 1.3 billion people are forecasted to work in virtual organizations within a few years (Johns \& Gratton, 2013). Virtual teams integrated via electronic means can offer effective solutions when product lifecycles are shortened and there are price

DOI: 10.4018/IJIDE.2015100102 
and fulfillment time related pressures, along with demands for higher quality, service, and customer responsiveness, and individualized productization (Lee-Kelley, 2002). In global companies, the possibilities of responding to the competition are often limited to leveraging existing in-house competencies, resources, and capabilities in new product projects quickly by forming global virtual teams (Cooper, 2011). Collaborative virtual teams can enable integration and the alignment of human resources to better tap into the external business environment (Nemiro et al., 2008).

Information in organizations is usually processed through integration mechanisms presented by Daft and Lengel (1986) consisting of documents, reports, databases, company strategies, meeting practices, and media offered for communication. However, new collaboration technology offers additional electronic platforms for communication in virtual teams allowing people to work together by using electronic tools such as e-mail, chat, and video conferencing (Te'eni et al., 2007; Brown et al., 2007). Communication's role is crucial and it has an effect on overall employee performance and job satisfaction (Pettit et al., 1997).

Companies require innovations, value, quality, and service and there is no room for inefficiency (Davenport \& Prusak, 2005). Thus, product development is usually very complex by nature and tremendous amounts of information must be transferred within the product development team(Ulrich \& Eppinger, 2000). However, there is the opportunity for collaborative work to be effectively arranged in various different ways in virtual organizations (Brown et al., 2007). Effective virtual collaboration has been referred to as virtual team competence by Hertel et al. (2005) and virtual competences by Wang and Haggerty (2009). In addition, Lohikoski and Haapasalo (2013) have suggested that virtual competences at the organizational and personal levels can enhance knowledge transfer in virtual NPD. Here, we have discussed how virtual collaboration competences can poten- tially enhance communication in virtual NPD. Research questions were formed as follows:

1. What are the characteristics of communication practices in virtual NPD?

2. What kinds of competences are needed to enhance communication?

The basis of this study lies in the virtual project team literature and in the virtual collaboration literature, which we aim to contribute to by refining theory from the perspective of virtual communication. In addition, we offer tools for those managing virtual organizations to increase efficiency in information sharing and collaboration among experts. A case study was conducted in a global telecommunication company with virtually operating global teams. Methodologically, we combined semistructured interviews and electronic surveys on selected team members and their leaders (project managers, line managers, and program managers) in Finland, Poland, China, and the United States. In addition to this, electronic survey data was collected and analyzed including team members located in seven different countries globally.

\section{THEORETICAL BACKGROUND}

\subsection{Definition of Virtual NPD Projects}

Virtual teams are geographically, organizationally, or otherwise dispersed collections of individuals who use different forms of ICT to accomplish a specific goal (Martins et al., 2004; Zigurs, 2003; Jarvenpaa et al., 2004). ICT enables the creation of new kinds of spaces that are real to the people inhabiting them, but they are not the same as physical locations (Lipnack \& Stamps, 2000). According to Kirkman and Mathieu (2005), even co-located teams can exhibit high levels of virtuality, because team members mainly use ICT in coordinating and 
executing work tasks, even if they are at the same location. Therefore, the physical location of the teams is not necessarily dominant in determining their virtuality.

The advances of virtual NPD teams combine the positive aspects of regular teamwork with flexibility and independency from time and space constraints, which enables the integration of remote locations and the benefit of expert knowledge. Most of all, market demands can be addressed more flexibly (Lipnack \& Stamps, 2000).

\subsection{Communication}

The goal for efficient communication in virtual teams is to generate action or change, or to create common understanding for organizational objectives (Faraj et al., 2011; Malhotra etal., 2007; Dennis et al., 2013; Snowden \& Boone, 2007; Cooper et al., 2004). Communication basically refers to team members' patterns of exchanging information and knowledge (Johns \& Gratton, 2013). Therefore, knowledge guides employees' thoughts, behavior, and communication (Spek van der \& Spijkervet, 1997). Several definitions of knowledge have been identified in the literature, but the most commonly used definitions in knowledge management studies are explicit and tacit knowledge. Nonaka and Takeuchi (1995) described formal knowledge as explicit knowledge that is easy to transmit between groups and individuals. It is usually represented in the form of specifications, codes, documents, numbers, or different kinds of formulas. Explicit knowledge is drawn from data that has been stored in information systems (Davenport \& Prusak, 2005). However, tacit knowledge - first identified by Polanyi (1958, 1966) - is personal knowledge, insights, knowhow, and deep understanding of contexts and it is usually hard to communicate formally to others. Choo (1998) has discovered that tacit knowledge is used by organization members in their work and in making interpretations of their world in general. It is hard to articulate, because it can mainly be used in action when doing tasks at work. Only human beings led by tacit knowledge have the capability to generate new knowledge. Choo (1998) has also added that tacit knowledge means intuition, judgment, and common sense-the capacity to accomplish tasks without questioning everything. With groups, tacit knowledge can exist in relationships, distinct practices, and social networks that emerge over time.

The quality of communication is crucial in organizations (Spek van der \& Spijkervet, 1997). In order to build strong interpersonal communication and relationships within organizations, a variety of competences are required. It is generally agreed by Bergiel et al. (2013), Holton (2013), Malhotra et al. (2007), and Snowden and Boone (2007) that written, verbal, oral, and cultural understanding and language skills are needed to ensure efficient communication between parties. Team members in virtual NPD projects are often multicultural, and therefore cultural and personality issues need to be considered when forming teams, sharing tasks, communicating, and giving feedback (Johns \& Gratton, 2013; Holton, 2001; Badrinarayanan \& Arnett, 2008; Gressgård, 2011; Faraj et al., 2011). It has also been strongly addressed in previous research that it is especially significant to understand development and the meaning of trust when communicating in virtual teams and when forming virtual teams (Malhotra et al., 2007; Vittal et al., 2010; Holste \& Fields, 2010; Mitchells \& Zigurs, 2009). Trust is needed because it has a link to power and power use. Knowledge is power and one does not share information without getting something in return. Culture affects in the way people deal with information and therefore communication needs to be managed carefully to enhance development of trust. (Huijser, 2006.) As a summary, it can be stated that communication in organizations is organized to: (1) enhance commitment, (2) generate change and action, (3) enhance the development of trust, and (4) transfer knowledge and information between teams and individuals. The success of organizations is often related to their ability to recognize different forms of information and knowledge and know how to utilize them in practice. 


\subsection{Communication Needs in NPD Projects}

Martins et al. (2004) conducted a literature review on virtual teams and suggested that moderators behind virtual team performance are organizational culture, leadership, support, and coaching, which have an impact on team processes that consist of planning and goal setting, communication actions, and interpersonal issues. Dietrich et al. (2013) found that some coordination practices are superior to others in an environment that is complex and rich in uncertainty.

Organizational communication systems are established to support information flow between employees and to support the whole organizational entity. Davenport and Prusak (2005) define information as messages that are meant to shape the message receiver's opinion or insights and to generally make a difference. Information is exchanged between individuals, and in addition, information systems have a link to customers and suppliers aside from the complex network of home organization (Te' eni et al., 2007). Te'eni et al. (2007), Brown et al. (2007), and Hertel et al. (2005) suggest that a project needs guidelines for communication; rules are needed on what information is shared and when and how team members are expected to communicate and how often. It is also essential to determine which tools are appropriate for team interaction. Efficient communication processes are also needed to prevent misunderstandings and conflict escalations. Also Ulrich and Eppinger (2000) and Lohikoski and Haapasalo (2013) emphasize the importance of communication coordination among activities between team members. Table 1 presents the relevant communication issues in common phases of the project.

Formal communication must be supported by informal communication that allows the development of collective values amongst team members. Ad hoc informal communication either face-to-face, through instant messaging, or chat - in a virtual office has been suggested as one of the most useful mechanisms in break- ing down individual and organizational barriers (e.g., Brown et al., 2007). Basically, communication has an input to tasks and norms, and communication affects the distance between the message sender and the receiver (Te'eni et al., 2007). In addition, there should also be a focus on management support systems, communication about expectations and objectives, and enough time for formal and informal discussions. Follow-up procedures also have significance (Brown et al., 2007). Miller (2006) also emphasizes technical and content reviews as essential factors in organizational information processing. Hertel et al. (2005) have emphasized the importance of providing clear success criteria and facilitating feedback processes across the distance.

\subsection{Communication Practices}

The amount, usability, and quality of ICT tools are crucial in virtual projects. Also important is the accessibility to technology and the quality and availability of databases and information systems (Miller, 2006; Zigurs, 2003). Information moves around organizations through hard and soft networks. A hard network has a visible and strict infrastructure; wires, delivery vans, satellite dishes, post offices, addresses, and electronic mailboxes. The messages that are transmitted via these tools are e-mails, traditional or paper mail, delivery service packages, and Internet transmissions. The soft network is less visible; it might be a note or an article given ad hoc (Davenport \& Prusak, 2005). Daft and Lengel(1986) describe organizational tools for communication as integrating mechanisms including various types of tools, strategies, documentation, and meetings related to, for example, decision-making, planning, and follow up. In addition, Lumsden and Lumsden (2004) have studied electronic systems, such as teleconferencing, video conferencing, online meeting systems, and collaborative groupware. Figure 1 describes the typical communication mechanisms in virtual NPD projects.

Davenport and Prusak (2005) have found that the amount of knowledge in an international 
Table 1. Characteristics of virtual NPD project teams'communication needs and practices

\section{Project Phase}

\section{Planning}

- Project vision, mission, priority, rules, and success criteria are established and communicated (Hunsaker \& Hunsaker, 2008; Martins et al., 2004). Members need to believe the team has an urgent and useful purpose. Clear rules of behavior need to be established (Katzenbach \& Smith, 2005).

- Setting up a reward system, defining the level of virtuality, and selecting proper ICT tools (Mukherjee et al., 2012; Hertel et al., 2005; Drouin et al., 2010).

- Technological requirements for communication are defined (Hunsaker \& Hunsaker, 2008; Martins et al., 2004).

Project initiation / kick off workshops

- Establishing and managing team boundaries, developing shared mental models, awareness, and motivation.

Managing communication processes and orienting to the task (Hunsaker \& Hunsaker, 2008; Martins et al., 2004).

- Relationship building phase. Testing and discovering norms and boundaries of what kind of behavior is acceptable (Tuckman, 1965). NPD demands enriched member interactions and greater group cohesiveness.

Promoting a sense of shared identity, cohesiveness, and technology use (Mukherjee et al., 2012; Drouin et al., 2010; Hertel et al., 2005).

Working phase, mid-stream

- Promoting communication, motivation, and knowledge management within the team. Managing virtuality-related problems (Mukherjee et al., 2012; Drouin et al., 2010).

- Steps are taken in initiations, managing team boundaries, and establishing working conventions and norms.

Ground rules are defined (Hunsaker \& Hunsaker, 2008).

- Group cohesion is found, establishing new group-generated norms and task conflicts are avoided to ensure harmony. The group can concentrate on the functional role-relatedness phase with problem solving skills and efficiency (Tuckman, 1965).

Lessons learned

- Rewarding and annotating success (Hunsaker \& Hunsaker, 2008; Zigurs, 2003).

- Recognizing achievements, considerateness of team members' needs. Re-integration of team often takes place again and therefore careful disbanding is important (Mukherjee et al., 2012).

company is often vast and scattered among offices and plants. They stated that knowledge is valuable only if it is accessible. It has also been suggested by Jong et al. (2007), Faraj et al. (2011), Li (2010), and Vanhala and Ahteela (2011) that the degree of synchronization of communication needs to be taken into account. In virtual team communication, different kinds of platforms for collaboration offer opportunities for working together. Also basic tools, such as e-mail, chat, or video conferencing are often used (Te'eni et al., 2007). Thus, Miller (2006) emphasizes how new communication technologies offer organizational participants a wide array of interaction possibilities that differ significantly from traditional work methods. Management support systems and decisionmaking options can also significantly differ from the ones at traditional work settings.
Face-to-face communication has the highest level of synchronization and advances in tacit knowledge transfer. Human and ICTrelated delays ought to be planned and taken into consideration when managing virtual NPD projects (Jong et al., 2007; Faraj et al., 2011). In addition, Hoefling (2008) states that face-toface meetings are often difficult to arrange due to time differences and financial restrictions, and therefore alternatives need to be identified to replace the richness of face-to-face communication. It is suggested that a crucial issue in communication is to choose proper tools and methods for communication.

\subsection{Virtual Collaboration Competence}

Bedwell et al.(2012) have suggested that collaboration is by definition based on reciprocity and shared goals in addition to the participation of 
Figure 1. Communication in virtual NPD projects

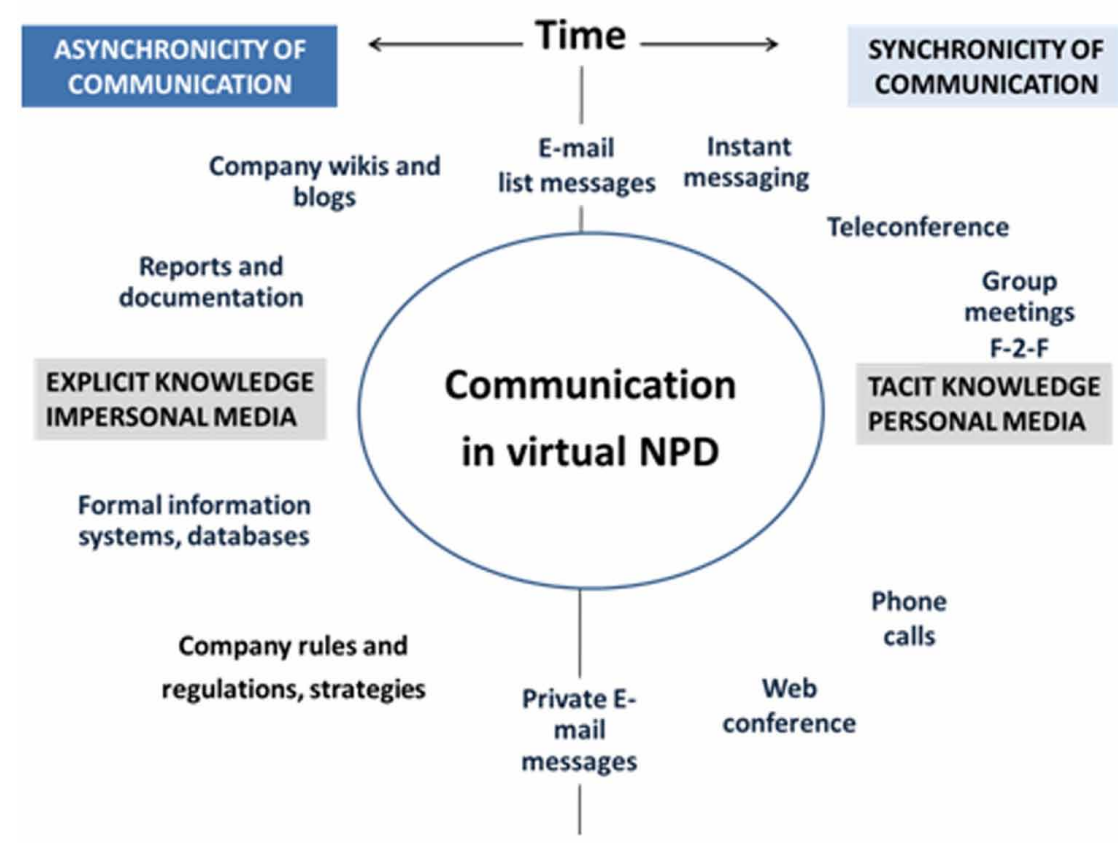

team members in joint activities. Collaborative teamwork is an evolving process incorporating also coordination, cooperation, and teamwork. Chiocchio (2011) suggests that collaboration basically enhances the positive effect of trust and therefore it improves team performance. In addition, task conflicts are reduced. With virtual collaboration competences, the information flows between individuals can be enhanced. On the contrary, without virtual collaboration competence, communication can lead to misunderstandings, inadequate information flow, and misinterpretations in different habits of exchanging information, which can cause harmful conflicts (Lohikoski \& Haapasalo, 2013). Anantatmula and Kanungo (2010) have stressed the point that virtual teams and organizations need individuals that are willing to participate extensively in conversations and individuals that have credibility and collectivist values. Therefore, cultural background and values can be significant for a team's success.
Wang and Haggerty (2009) have also suggested that new skills for working successfully in virtual organizations are needed. There are some essential issues that affect virtual competencies. Face-to-face meetings and training for virtual work can help to overcome the problems in technology. Also technology skills and general familiarity with lean media are important. In addition to this, informal communication between team members is needed in order to create interpersonal relations with team members, which is also what Malhotra et al. (2007) and Luther and Bruckman (2011) have discovered. In addition, they highlight that it is very difficult to co-operate in virtual organizations without knowing colleagues personally at some level. In sharing documents and materials, Malhotra et al. (2007) have suggested shared rules for sharing and versioning the documents and rules for when to comment and communicate on the team's work. The structure of the meetings is also very important in order to secure efficient communication. In addition to this, Zigurs 
Figure 2. Relationship between OVCC, PVCC, and communication practices

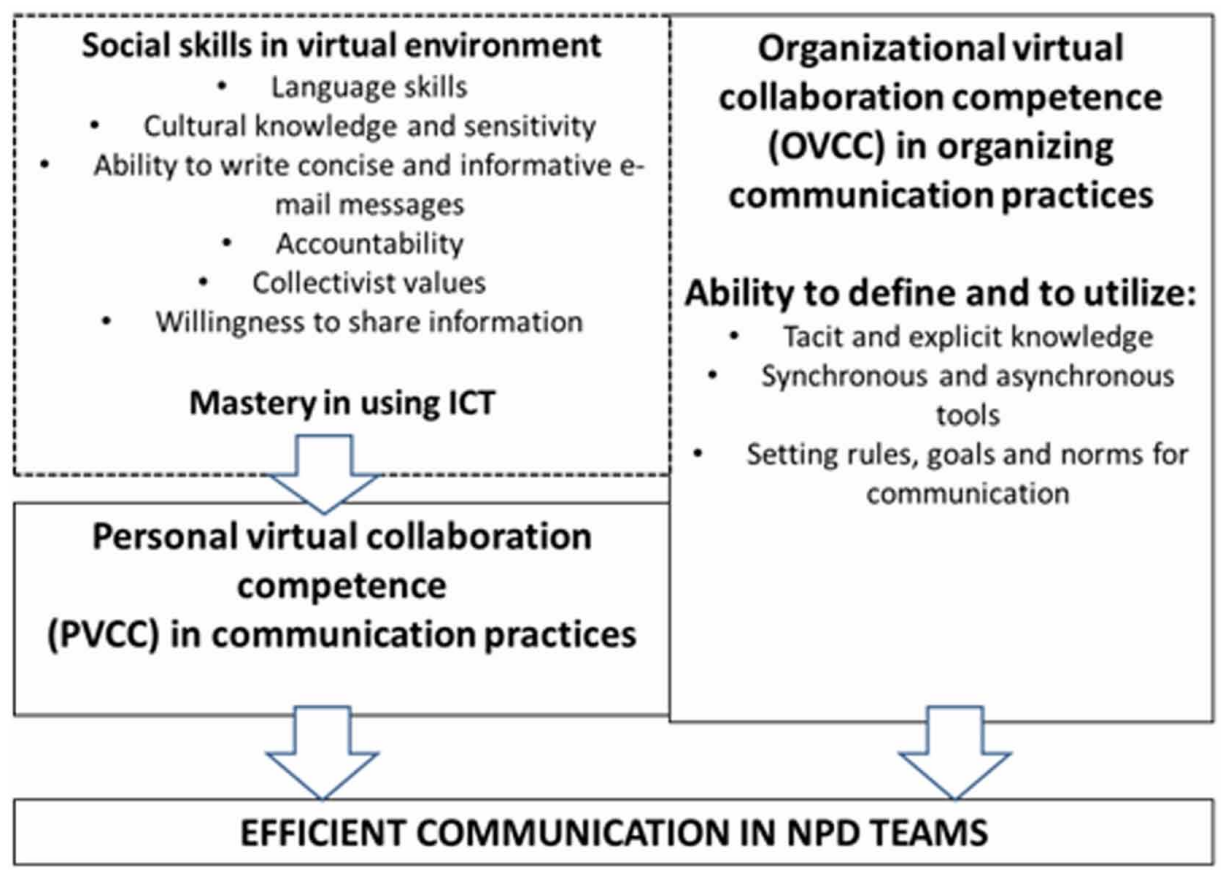

(2003) has emphasized the significance of explicit training in communication practices and cultural issues. According to previous studies by Lohikoski and Haapasalo (2013), training in communication practices should especially focus on cultural and communication issues, such as writing clear and structured e-mail messages. Also concentrating on fact-based communication is beneficial in virtual communication and when solving conflicts. Active communication on goals, active follow up, and various ways of giving feedback play a significant role in the success of virtual teams. Active leader presence in the virtual environment plays a significant role.

Faraj et al. (2011) have discovered that by combining people with strong expertise and strong vision together, great innovations can be achieved in new products and processes, but passionate work orientation can also create problems. In addition to this, cultural differences can challenge the virtual team's success, if not managed properly. Therefore, appropri- ate management skills, negotiation skills, and training for virtual work are needed. Hertel et al. (2005) have emphasized virtual team competency that includes conscientiousness, integrity, co-operativity, communication skills, and selfmanagement skills in addition to cross-cultural skills and the ability to build interpersonal trust. Communicating about goals and team roles is also crucial for team performance. Figure 2 describes the personal virtual collaboration competence (PVCC) and organizational virtual collaboration competence (OVCC).

\section{CASE STUDY: COMMUNICATION IN VIRTUAL NPD PROJECTS}

\subsection{Multi-Method Case Study}

Multi-method case study was designed through a case study approach combining literaturebased semi-structured interviews and also electronically obtained survey data. Yin (2009) 
Figure 3. Theoretical framework for the study

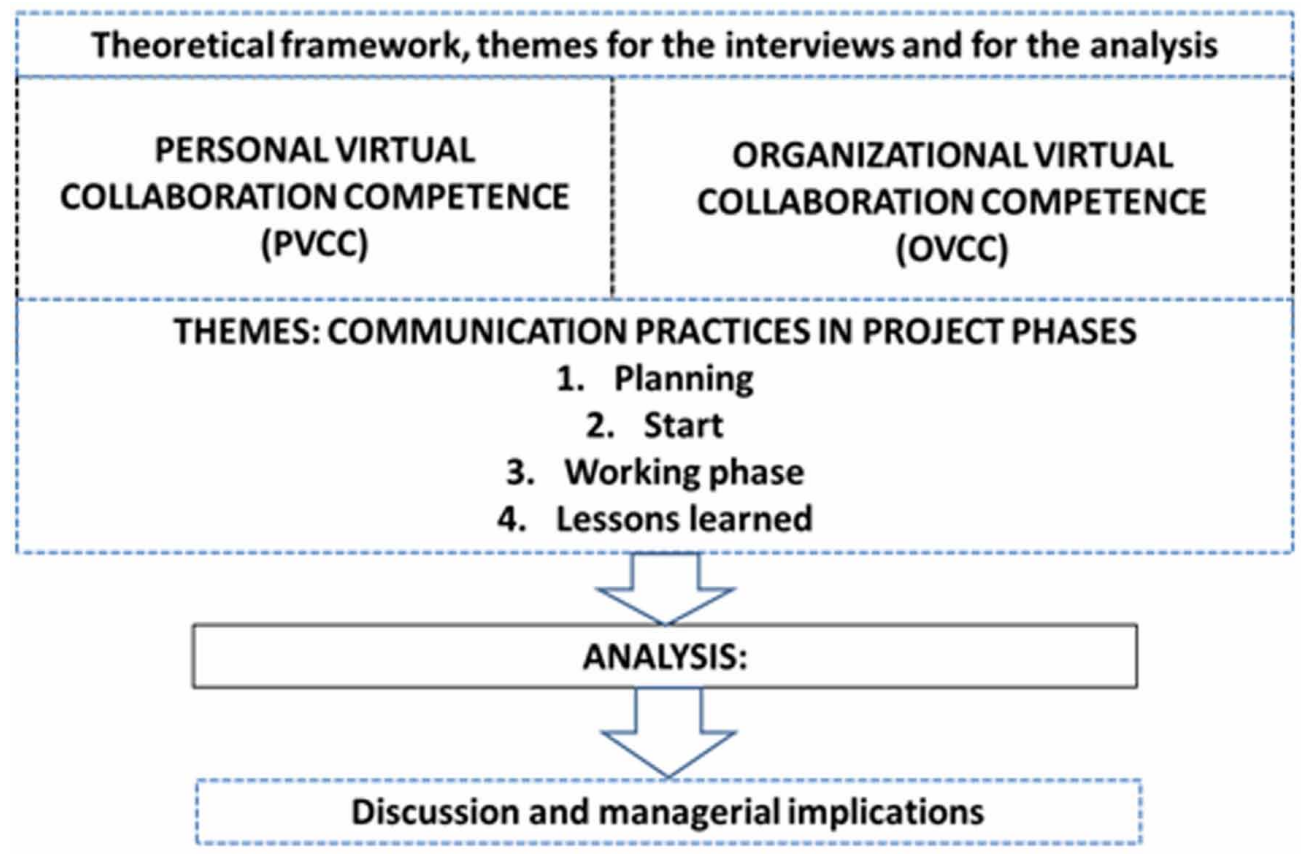

emphasizes the relevance of the case study for research and also the significance of trust from the informants to acquire valid and reliable data for research. In management studies, case studies can identify key factors, new competencies, logics, and sources related to dynamic and organizational capabilities (Ridder et al., 2009). In research design, phase themes for the interviews and methods were designed separately; however, in analyzing and interpreting the results, the research data was handled both separately and together. Qualitative and quantitative data were used to complement each other. The theoretical framework and the central themes for the interviews and the analysis are presented in Figure 3.

Components of the study units of communication needs in different phases of the NPD project presented in figure 3 are described more specifically as follows:

1. Planning: Asynchronous or synchronous tools in planning procedures, meetings, decision making, selecting team members, communication infrastructure, rules and norms for communication, selecting ICT tools, considering cultural backgrounds, considering professional background.

2. Start: Kick off meeting practices, decision making, deciding rules and norms for communication, team building practices.

3. Working Phase: Access to relevant information, decision making procedures, support mechanisms, strengths and problems in virtual communication, meeting practices.

4. Lessons Learned: Best practices for virtual team's communication, characteristics for efficient team member, team spirit, quality of communication, lessons learned practices.

Finally results were analyzed and enriched with the survey data. In addition, managerial implications were suggested based on both theory and for practice. 


\subsubsection{Qualitative Semi- Structured Interviews}

The themes for the interviews are based on communication practices in virtual organizations, the division which was also used in processing the research data. Altogether, 11 leaders and 12 expert teams were interviewed at sites in the USA, Finland, China, and Poland in order to obtain reliable data on the studied phenomena. The teams in Finland were interviewed face-toface with participants also via teleconference. The teams in America, China, and Poland were interviewed in a web-conference meeting room, which is very similar to a face-to-face meeting. Each interview was recorded. The team interviews took from 50 minutes to two hours and 15 minutes, and the leader interviews took from 35 minutes to over one hour, depending on the informants. The content was analyzed by using the theoretical framework of this study to answer the research questions. Qualitative data was diverse, deep, complex, and subtle, as Seale et al. (2004) have described some of the characteristics of good qualitative research.

\subsubsection{Electronic Survey}

Quantitative data was collected via survey. Informants were invited to participate in the survey via e-mail, also two additional reminders were sent to potential participants during the study. Two online electronic surveys were active for five months, 94 employees completed the questionnaire with a $69 \%$ response rate. Webropol, an Internet-based survey program was used and participants could complete the survey only once. The questionnaire was built on interview themes and a 4-point Likert scale was used. Data was processed in Excel sheets.

\subsection{Organization}

The case study organization is a leading global enabler of telecommunications services operating in 150 countries. With its focus on sustainability and innovation, the company provides a comprehensive portfolio of network technologies, as well as services including con- sultancy and systems integration, deployment, maintenance, and managed services. The case organization was selected for the study, because it has multinational and multisite virtual ways of working as an everyday routine. We have a long-term research relationship with the case company in addition to the researcher's prior work experience in the same organization.

The informants were a rich selection of virtual team members with titles such as line managers, project managers, program managers, senior specialists, and chief engineers. Nationality of the informants based on the survey was $29 \%$ China, $18 \%$ USA, $34 \%$ Finland, $12 \%$ Poland and 7\% were from Great Britain, India and Germany. Most relevant background information is work experience in virtual projects, which was divided between $54 \%$ having less than 10 years of experience into $29 \%$ of those with having 10-14 years of experience. What was also interesting was that $11 \%$ had $15-19$ years of experience in virtual projects and $7 \%$ had over 20 years of experience. Characteristics of the informants are described more in detail as pie charts in appendix 2 .

\subsection{Planning and Starting the Project}

Originally, project proposals come from the upper management and those proposals are further discussed at each site. Schedules, goals, guidelines, and financial decisions for the projects also come from the management; however, teams have a chance to review the information. After review meetings, teams can consider if they have enough resources and they further plan how the targets are going to be achieved. All leaders and team members agreed with this practice, and it was also considered as the most efficient way to organize projects. However, more involvement in decision-making regarding financing was desired by two managers in Finland. Basically, the framework for the projects is set by the management; however, team leaders need to prepare the project for the review, as Manager $\mathrm{C}$ in America described: 
Okay, if I take 10 people to the room and say "let's make a plan", it does not work out. The leader needs to set the frames and then have that discussion. The leader needs to make a plan first and then have team members to discuss and then to decide. You can't come to the room empty-handed and then try to make a plan; that never works.

ICT tools for the project are usually the same that project managers have previously used; however, some teams and leaders mentioned an official communication plan that defines the tools to be used. However, the influence of previous communication practices is stronger than the official process. Projects have been started within a past without face-to-face interaction, which was considered harmful and difficult among informants from the information sharing perspective. Informants in Finland described a project with members in China, that project was started, but employees did not actually start working until they had traveled to meet each other in person. According to leaders in all sites, setting goals, enhancing commitment, and leading people is significantly more difficult in virtual projects without face-to-face communication first, and without knowing the project members personally at some level, as Leader B in Finland describes:

You have to see those people face-to-face at the planning. There you can see who is capable of accomplishing tasks successfully and who needs more guidance. With some team members, you can't trust if he has handled the tasks, as he was supposed to. So I have to follow up and check and again re-check.

It was clearly mentioned by all informants in all sites that face-to-face communication is crucial at least at the beginning of the project. After communicating face-to-face, it is easier to interpret team members' tone of voice and facial expressions when communicating virtually as members in team $B$ and team C in Finland described more specifically. Considering issues with more in depth and technical complexity, teams' preferences of communication methods varied between sites, but also within sites. Especially e-mail divided opinions.

\subsection{Asynchronous Communication at the Working Phase}

According to the interviewees, the most frequently used communication channels at the working phase of the project were e-mails and meetings. Project members in China and in the USA relied mostly on e-mail communication. According to some employees, it was easy to use e-mail on complex issues especially when team members' company language skills were not adequate. It was also stated that complex technical issues were easier to communicate through documentation or e-mail, especially due to time differences between the USA and China and due to inadequate company language skills. The other half of the informants considered phone calls or web-conferences as a better option, or if possible, a face-to-face meeting. Also e-mail list messages and mass e-mails divided opinions, some informants considered them useful for sharing information, whereas others suggested e-mail lists should be forbidden, because the amount was considered vast. For information sharing, the company had several communication practices, which varied between sites. However, meetings were considered least effective for this purpose and information letters were most wanted. Table 2 presents the summary of the case company's asynchronous communication practices.

\subsection{Synchronous Communication at the Working Phase and Finalizing the Project}

Transferring tacit knowledge is possible in virtual projects. According to the survey, $43 \%$ partly agreed and $18 \%$ agreed with the statement "transferring advanced professional knowledge via ICT is not a problem". Only $11 \%$ disagreed with this statement. Based on the interviews, meetings are usually teleconferences with a possibility to share documents 


\section{Table 2. Asynchronous communication}

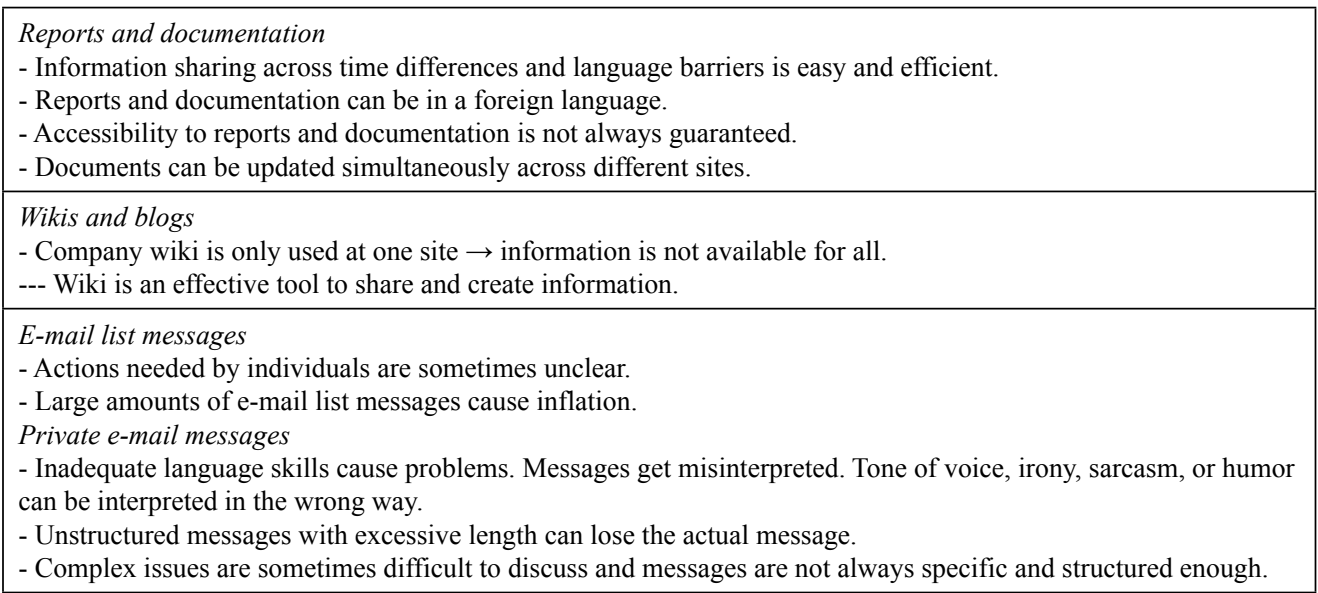

and reports virtually. Secondly, phone calls and web-conferences were used, in addition to company wiki and chat. Also sharing documents, reports, and backlogs of questions and answers, in addition to face-to-face meetings were mentioned as fundamental and efficient information and knowledge sharing practices. Efficiency in virtual meetings at the working phase of the project was considered somewhat of a problem in the USA and in Finland based on the interviews. For the statement in the survey: "Managers perform efficiently in virtual meetings", $14 \%$ of the informants agreed, $47 \%$ partly agreed, and $32 \%$ partly disagreed. Virtual meetings were considered well-structured and useful by $22 \%$, and $49 \%$ partly agreed with this statement based on the survey. Based on interviews, virtual meetings were seen as inefficient especially when they were used primarily for sharing explicit knowledge as Team $\mathrm{C}$ in Poland described:

Meetings are also often overused because they are used for the information sharing. If you want to just share the information, please store it somewhere. And if someone will need it, will take it. Status meetings are something very inefficient.
Daily or weekly meetings were also considered an efficient way to share information especially when there were delays or problems with communication, as Leader B in Poland describes:

We are working in Scrum and they advise to have daily meetings. Five of the members are sitting next to each other, so we sometimes skip the meetings. I think it's best that they communicate how they want by chat, by e-mail, by telephone. I'm happy to see them communicating freely. But when I don't see the communication, then we will meet once a week. If communication is not working, people from China are sending e-mails, people from Poland are also sending e-mails, so communication is stuck in e-mail. Then I'm saying, you cannot communicate like this. We need to set some, sync meeting every day, 15 minutes or something.

Web-conferences with the physical presence of the meeting participants were not regularly used among informants. There is only one web-conference room enabling face-to-face like contact at each site, which usually needs to be reserved well in advance. The significance of face-to-face like communication at the beginning of the project was agreed by all informants; however, alternative tools were not available 


\section{Table 3. Synchronous communication}

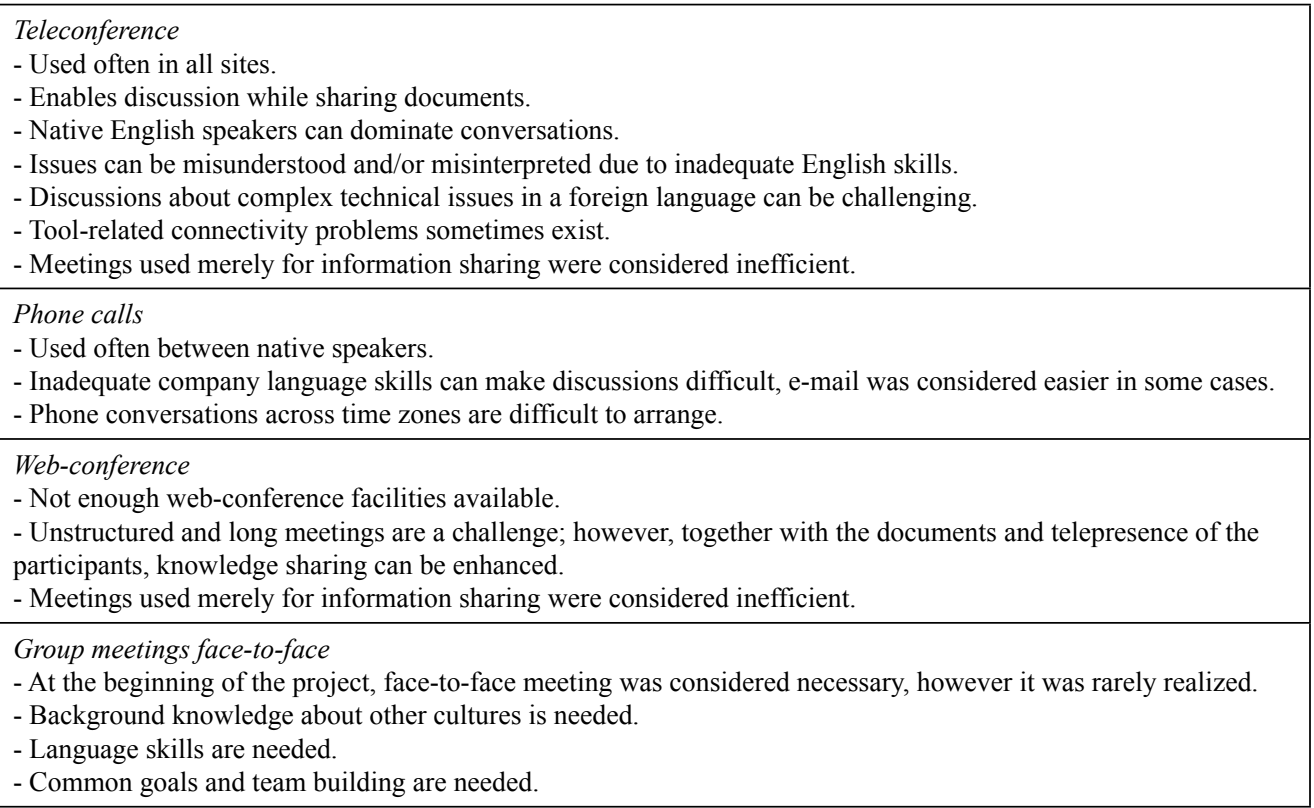

or informants had not adopted them as part of their communication repertoire. Communication skills in general were defined as adequate for working in virtual teams. Of the informants, $67 \%$ agreed and $26 \%$ partly agreed with the statement "My ICT skills are sufficient for working in virtual teams". In addition, informants estimated their own communication skills in the virtual environment as mostly adequate. For the statement "I have good communication skills in the virtual environment", $48 \%$ agreed, $41 \%$ partly agreed, and $11 \%$ partly disagreed. Table 3 describes synchronous communication practices.

The usability of company ICT tools was considered adequate among all the interviewed informants. There have been connection problems in the past, but nowadays teleconferences are seen to work well. Also, the survey showed similar results. For the statement "ICT tools support and make my work easier", $32 \%$ agreed and $47 \%$ partly agreed. However, there were informants that partly disagreed $(19 \%)$ or disagreed $(2 \%)$ with this statement. According to the interviews, there are company-level social collaboration platforms and knowledge sharing databases, but most of the informants in all sites stated that it is not clear who is using them or why employees should use them. Social collaboration platforms were mentioned to be used only in China; however, in other sites there seemed to be a lot of variety about which databases and platforms are used and for what purpose. After projects, lessons learned documents are made and reviewed with the key project members and stakeholders. Documents are stored in company databases for further use. Also communication issues get reviewed and communication practices for new projects are tailored based on previous project's lessons learned outcomes.

The greatest communication problem based on the interviews is related to the clarity of shared goals and norms in communication between $\mathrm{HW}$ and SW, and generally the clarity of shared goals between sites. Whenever there were delays in schedules, changes in original project plans, or technical problems, the clarity of common goals is seen to disappear. Relationship based problems was the second 
biggest problem consisting of challenges relating mainly to inadequate language skills, which cause misunderstandings, conflicts, and decreases in the virtual team performance, causing frustration among team members. Also, unclear communication without clear focus and cultural differences add potential misunderstandings. In addition, information overload in e-mail messaging and inefficiency in virtual meetings were significant problems based on interviews. E-mail messaging related problems are tangled together with relationship based conflicts, which result from unclear messages that are easily interpreted the wrong way. Cultural background was mentioned by all the informants to significantly influence both sending and receiving information.

\section{DISCUSSION}

Research within the field of knowledge management in past decades has indicated that tacit knowledge related to complex technical issues is difficult to transfer virtually. It has been indicated that physical presence is often needed to enhance care and commitment between employees, which is needed for knowledge creation and communication, as Nonaka and Takeuchi(1995) have studied. Thus, Davenport and Prusak (2005) have stated that managers get most of their information in face-to-face and phone conversations. However, recent research by Lohikoski and Haapasalo (2013), Hertel et al. (2005), and Wang and Haggerty (2009) have started to indicate that skills related to organizational and personal virtual collaboration competence enhance virtual communication and even tacit knowledge transfer among global teams. We suggest that effective teamwork can be accomplished and managerial tasks completed successfully through personal and organizational virtual collaboration competence, which can develop within years of working together in virtual settings and through systematic training. Davenport and Prusak (2005) have presented that the power of knowledge is to organize, select, and prioritize and it comes from experience and values, more often than from intelligence and education. Knowledge is a corporate asset and therefore it is crucial to consider how communication is organized.

Global cross-cultural projects have changed the working environment significantly and it is crucial to recognize what kind of communication is needed in each phase of the project. Extensive experience in cross-cultural virtual collaboration itself can be tacit knowledge, on for example, how to give and receive feedback and how to share tasks across different cultures and across organizational boundaries through ICT. This can be referred to as tacit knowledge that can exist in relationships, practices, and social networks that emerge over time, which is in line with previous research by Choo (1998).

The case company's most frequently used communication practices during the lifecycle of a project are e-mail and meetings. Also telephone, teleconferences, and web-conferences are used in addition to wikis in Poland. There was variety among different sites concerning which tools were used and which ones were considered effective and for which purpose. However, there were also differences in opinion within sites and within teams, for example, regarding the use of e-mail messaging. Some informants considered e-mail as useful and an easy communication method even in complex issues, whereas others considered it harmful, a potential cause for misunderstandings and even conflicts. Also, all team interviews and most leader interviews emphasized how inadequate language skills are hindering information processing in meetings and in e-mail messaging. However, unstructured e-mails, large quantities and excessive length in e-mail messages were also listed among the most common problems. It has not been acknowledged among informants that some tools are more suitable for transmitting tacit knowledge than others. Asynchronous tools might not be the best possible option for communicating about complex technical issues, topics consisting of feelings, or topics high in equivocality. Therefore, teams might benefit from acknowledging the differences between different types of information, choosing the 
right tool for each purpose, and defining rules for using them. It would also be beneficial to define response times to e-mail messages beforehand in order to avoid conflicts and delays, which is also what previous research by Malhotra et al. (2007) suggests. For a message sender, not receiving a response might mean a variety of things from forgetting to neglecting a message. Also Te'eni et al. (2007) suggest that silence can mean for example, technical problems, hesitation, or even anger. In virtual communication, it is typical that goodwill is hard to observe and humor is hard to interpret, also expectations about actions and the actions themselves are not visible.

Based on our study, we propose that a crucial part of virtual collaboration competence is to recognize one's own characteristics in virtual communication practices. Willingness to improve collaboration competences through training would benefit virtual team members. The most crucial virtual collaboration competences at a personal level include mastery of using ICT and social skills in a virtual environment, which includes adequate company language skills, competence in writing succinctly, and structuring e-mail messages. Also cultural knowledge and sensitivity play a significant role, which can enhance communication significantly as presented previously by Lohikoski and Haapasalo (2013). More specifically, giving feedback and sharing tasks with people from different organizational and cultural backgrounds need to be carefully considered, which is in line with the previous studies of Bergiel et al. (2013), Johns and Gratton (2013), Holton (2001), Faraj et al. (2001), and Chen et al. (2011). Knowledge sharing behavior is important, and this can be affected through giving feedback and rewarding collaborative behavior. In addition to personal virtual collaboration competences, guidelines for response times in sharing e-mails and for giving and collecting feedback should be negotiated and agreed upon amongst project members. Also, rules in sharing documents, reports, and information letters would be beneficial to define and agree upon both on the project and company levels.
Organizational virtual collaboration competences (OVCC) include information systems, knowledge management practices, and communication processes for knowledge work that enhance and encourage knowledge sharing among experts. The enhancement can be enabled through training and through feedback and rewarding processes that support virtual team building. Hertel et al. (2005) have also suggested that there is a strong need for clear communication about goals and team building virtually. Also careful planning and collaboration processes are needed to prevent misunderstandings and conflict escalations. Previous research by Sias et al. (2012) suggests that managers should provide an opportunity for face-to-face communication whenever possible. This is especially crucial at the beginning of the project, as also emphasized by Zigurs (2003), Wang and Haggerty (2009). Meetings in the form of a web-conference or teleconference also provide an alternative opportunity for face-to-face interaction, and therefore enhance relations between coworkers. This is, if they are used systematically and employees are trained in using them instead of traditional methods of communication. Figure 4 describes the potential consequences of virtual collaboration competence, which have a direct impact on team performance and success.

\section{CONCLUSION}

Virtual teams are increasingly common in global business, offering more possibilities to benefit from experts working across the globe. Communication in organizations is organized to enhance commitment, manage change, generate action, create common understanding, enhance the development of trust, and simply to transmit knowledge and information between teams and individuals. The current research project attempted to study and analyze virtual collaboration competences in virtual NPD through investigating the case company's communication practices. 


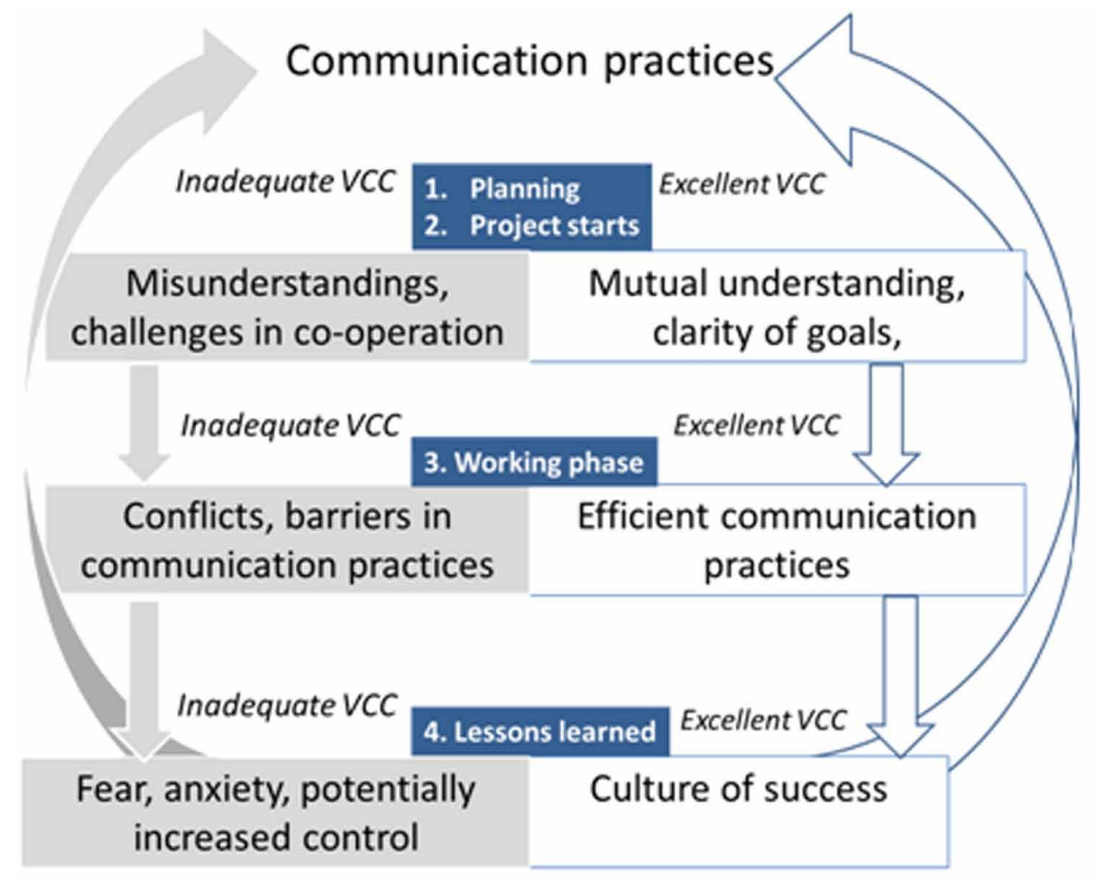

The communication practices were characterized by complexity and various different ways in operating based on project managers' and team members' prior experiences and preferences rather than specific predefined communication processes. The most frequently used communication methods were e-mail messaging and meetings; however, phone calls and company wiki were also used. With more efficient use of web-conferences and with better planning and structure of virtual meetings, communication could be improved. Characteristics of communication were also accessibility prob- lems to certain databases among informants. Face-to-face communication was very limited, which inflicts additional challenges on projects. In addition to the undefined processes, the most significant issues influencing communication practices in the case company were inadequate language skills and lack of shared rules and norms in e-mail messaging, but generally issues in sharing information. Based on the interviews and survey, the company tools were considered efficient and up-to-date, but there were not enough tools enabling face-to-face like contact

\section{Table 4. Advantages of asynchronous virtual communication}

- Testing of the product can be conducted $24 / 7$ and test results can be shared continuously across time zones.

- Option to update documents simultaneously across different sites.

- Information can be shared widely across organizations.

- E-mails enable communication for those with inadequate oral English skills.

- Increases efficiency and flexibility of experts' work, as information does not need to be shared at the meetings.

- Introverts may find it easier to collaborate through asynchronous tools.

- Negative effects of cultural differences related to physical presence are decreased. 
in these sites. Basically, more web-conferences are needed to replace face-to-face meetings.

It is proposed that virtual collaboration competence at the personal and organizational levels enhances communication, which also enables communicating about complex technical issues. At the organizational level, the competences are knowledge management practices that enhance the development of trust and knowledge sharing among team members and information systems that support collaborative virtual work. In addition, efficient communication processes are needed to guide team members in information intensive organizations. At the personal level, the suggested virtual collaboration competences are abilities to write clear and succinct e-mail messages while taking the recipient into account, virtual social skills including cultural sensitivity and language skills, media skills, and mastery in using ICT. In addition, it is suggested that communication would be easier and more efficient to manage with better knowledge of the advantages and disadvantages of transferring different types of knowledge through ICT. In summary, the advantages of using virtual asynchronous communication tools are presented in Table 4.

When evaluating this study, it should be noted that the empirical data was collected only from one case company. However, it should also be noted that the case company has a long history and experience in carrying out virtual projects. It is also notable that virtual team members and leaders that were selected for the study had a variety of experience in virtual projects from $31 \%$ having over 20 years of experience up to $29 \%$ of less than 10 years of experience. Therefore, information from the survey and from the interviews is considered rich in many ways - presenting various perspectives across the company and across countries and cultures in different sites. However, future studies should focus on several different companies in different fields of business and possibly also in education and government to shed more light on this complex topic of personal and organizational virtual collaboration competence. Moreover, the means of overcoming challenges related to synchronicity and asynchronicity in communication should also be studied in more detail. In addition, further studies are needed to ascertain the variety of personal and competence related reasons behind employees choosing certain tools for certain tasks in virtual NPD.

\section{REFERENCES}

Anantatmula, V. S., \& Kanungo, S. (2010). Modeling enablers for successful KM implementation. Journal of Knowledge Management, 14(1), 100-113. doi:10.1108/13673271011015598

Badrinarayanan, V., \& Arnett, D. B. (2008). Effective virtual new product development teams: An integrated framework. Journal of Business and Industrial Marketing, 23(4), 242-248. doi:10.1108/08858620810865816

Bedwell, W. L., Wildman, J. L., DiazGranados, D., Salazar, M., Kramer, W. S., \& Salas, E. (2012). Collaboration at work: An integrative multilevel conceptualization. Human Resource Management Review, 22(2), 128-145. doi:10.1016/j.hrmr.2011.11.007

Bergiel, B. J., Balsmeier, P. W., Bergiel, B., \& Erich, B. (2013). Nature of virtual teams: A summary of their advantages and disadvantages. Management Research News, 31(2), 99-110. doi:10.1108/01409170810846821

Brown, K. M., Huettner, B., \& James-Tanny, C. (2007). Managing virtual teams: Getting the most from wikis, blogs, and other collaborative tools. Texas: Wordware Publishing.

Chiocchio, F., Forgues, D., Paradis, D., \& Iordanova, I. (2011). Teamwork in integrated design projects: Understanding the effects of trust, conflict, and collaboration on performance. Project Management Journal, 42(6), 78-91. doi:10.1002/pmj.20268

Choo, C. W. (1998). The knowing organisation-How organisations use information to construct meaning, create knowledge and make decisions. New York: Oxford University Pres.

Cooper, R. G. (2001). Winning at new products: Accelerating the process from idea to launch. Cambridge, Massachusetts: Perseus Publishing.

Cooper, R. G., Edgett, J. S., \& Kleinschmidt, J. E. (2004). Benchmarking best NPD practises - I. Research Technology Management, 47(1), 31-43. 
Daft, R. L., \& Lengel, R. H. (1986). Organizational information requirements, media richness and structural design. Management Science, 32(5), 554-571. doi:10.1287/mnsc.32.5.554

Davenport, T. H., \& Prusak, L. (2005). Working Knowledge: How Organizations Manage What They Know. Ubiquity An ACM IT Magazine and Forum. 11.2.2005 1-15.Available online: http://wang.ist.psu. edu/course/05/IST597/papers/Davenport know.pdf

Dennis, D. J., Meola, D., \& Hall, M. J. (2013). Effective leadership in a virtual workforce. American Society of Training and Development, 67(2), 46-51.

Dietrich, P., Kujala, J., \&Artto, K. (2013). Inter-team coordination patterns and outcomes in multi-team projects. Project Management Journal, 44(6), 6-19. doi:10.1002/pmj.21377

Drouin, N., Bourgault, M., \& Gervais, C. (2010). Effects of organizational support on components of virtual project teams. International Journal of Managing Projects in Business, 3(4), 625-641. doi:10.1108/17538371011076082

Faraj, S., Jarvenpaa, S. L., \& Majchrzak, A. (2011). Knowledge collaboration in online communities. Organization Science, 22(5), 1124-1239. doi:10.1287/ orsc. 1100.0614

Gressgård, L. J. (2011). Virtual team collaboration and innovation in organisations. Team Performance Management, 17(1), 102-119. doi:10.1108/13527591111114738

Hertel, G., Geister, S., \& Konradt, U. (2005). Managing Virtual Teams: A review of current empirical research. Human Resource Management Review, 15(1), 65-95. doi:10.1016/j.hrmr.2005.01.002

Hoefling, T.(2008). The three-fold path of expanding emotional bandwidth in virtual teams. In J. Nemiro, M. Beyerlein, L. Bradley, \& S. Beyerlein (Eds.), The handbook of high performance virtual teams. A toolkit for collaborating across boundaries. San Francisco, US: John Wiley \& Sons.

Holste, S. J., \& Fields, D. (2010). Trust and tacit knowledge sharing and use. Journal of Knowledge Management, 14(1), 128-140. doi:10.1108/13673271011015615

Holton, J. A. (2001). Building Trust and Collaboration in a Virtual Team. Team Performance Management: An International Journal, 7(3/4), 36-47. doi:10.1108/13527590110395621

Huijser, M. (2006). The cultural advantage: A new model for succeeding with global teams. Amsterdam: Nicholas Brealey Publishing.
Hunsaker,P.L., \&Hunsaker,J.S.(2008). Virtualteams: A leaders guide. Team Performance Management, 14(1/2), 86-101. doi:10.1108/13527590810860221

Jarvenpaa, S. L., Shaw, T. R., \& Staples, S. D. (2004). Toward contextualized theories of trust: The role of trust in global virtual teams. Information Systems Research, 15(3), 250-267. doi:10.1287/isre.1040.0028

Johns, T., \& Gratton, L. (2013). Spotlight on the future of knowledge work: The third wave of virtual work. Harvard Business Review, 91(1), 66-73.

(2008). Jong de, Remco, Schalk, Réne, Curseu, Petru L. (2007). Virtual communication, conflicts and performance in teams. Team Performance Management, 14(7/8), 364-380. doi:10.1108/13527590810912331

Katzenbach, J. R., \& Smith, D. K. (2005). Best of HBR 1993. The discipline of teams. Harvard Business Review. High Performance Organization, July-August, 1-10.

Kirkman, B. L., \& Mathieu, J. E. (2005). The Dimensions and Antecedents of Team Virtuality. Journal of Management, 31(5), 700-718. doi:10.1177/0149206305279113

Lee-Kelley, L. (2002). Situational leadership: Managing the virtual project team. Journal of Management Development, 21(6), 461-476. doi:10.1108/02621710210430623

Li, W. (2010). Virtual knowledge sharing in a crosscultural context. Journal of Knowledge Management, 14(1), 38-50. doi:10.1108/13673271011015552

Lipnack, J., \& Stamps, J. (2000). Virtual teams: People working across boundaries with technology. Toronto, Canada: John Wiley \& Sons.

Lohikoski, P., \& Haapasalo, H. (2013). Virtual competencies and knowledge transfer in global NPD. International Journal of Management. Knowledge and Learning, 2(2), 185-207.

Lumsden, G., \& Lumsden, D. (2004). Communicating in Groups and Teams. Sharing Leadership (4th ed.). Belmont: CA Thomson Wadsworth.

Luther, M., \& Bruckman, A. (2011). Leadership and success factors in online creative collaboration. IEEE Potentials, 6(5), 27-32. doi:10.1109/ MPOT.2011.941499

Malhotra, A., Majchrzak, A., \& Rosen, B. (2007). Leading virtual teams. The Academy of Management Perspectives, 21(1), 60-70. doi:10.5465/ AMP.2007.24286164 
Martins, L. L., Gilson, L. L., \& Maynard, T. M. (2004). Virtual teams: What do we know and where do we go from here? Journal of Management, 30(6), 805-835. doi:10.1016/j.jm.2004.05.002

Miller, K. (2006). Organizational communication: Approaches and processes (4th ed.). Belmont, CA, USA: Thomson Wadsworth.

Mitchell, A., \& Zigurs, I. (2009). Trust in virtual teams: Solved or still a mystery? The Data Base for Advances in Information Systems, 40(3), 61-83. doi:10.1145/1592401.1592407

Mukherjee, D., Lahiri, S., Mukherjee, D., \& Billing, T. K. (2012). Leading virtual teams: How do social, cognitive, and behavioral capabilities matter? Management Decision, 50(2), 273-290. doi: $10.1108 / 00251741211203560$

Nemiro, J., Bradley, L., Beyerlein, M., \& Beyerlein, S. (2008). The challenges of virtual teaming. In J. Nemiro, M. Beyerlein, L. Bradley, \& S. Beyerlein (Eds.), The handbook of high performance virtual teams: A toolkitfor collaborating across boundaries. San Francisco, US: John Wiley \& Sons.

Nonaka, I., \& Takeuchi, N. (1995). The knowledge creating company. Oxford: Oxford University Press.

Pettit, J. D. Jr, Goris, J. R., \& Vaught, B. C. (1997). An examination of organizational communication as a moderator of the relationship between job performance and job satisfaction. Journal of Business Communication, 34(1), 81-98. doi:10.1177/002194369703400105

Polanyi, M. (1958). Personal knowledge: Towards a post-critical philosophy. Chicago, IL: Chicago University Press.

Polanyi, M. (1966). The tacit dimension. London: Routledge Keagan.

Ridder., . . .. (2009). The theoretical contribution of case study research to the field of strategy and management. In D. D. Bergh, \& D. J. Jr. Ketchen (Eds.), Research methodology in strategy and management. UK: Emerald JAI Press. doi:10.1108/ S1479-8387(2009)0000005007

Seale, C., Gobo, G., Gubrium, J., \& Silverman, D. (2004). Qualitative Research Practice. The Trowbridge. Wiltshire: Cromwell Press Ltd. SAGE Publications Ltd.
Sias, P. M., Pedersen, H., Gallagher, E. B., \& Kopaneva, I. (2012). Workplace friendship in the electronically connected organization. $\mathrm{Hu}$ man Communication Research, 38(3), 253-279. doi:10.1111/j.1468-2958.2012.01428.x

Snowden, D. J., \& Boone, M. E. (2007). A leader's framework for decision making. Harvard Business Review, (November): 1-9. PMID:18159787

Spek van der. R., \& Spijkervet,A. (1997). Knowledge management: Dealing intelligently with knowledge. In J. Liebowitz, \& L. C. Wilcox (Eds.), Knowledge management and its integrative elements. Boca Raton, FL: CRC Press.

Te'eni, D., Carey, J., \& Zhang, P. (2007). Human computer interaction: Developing effective organizational information systems. Hoboken, NJ, USA: John Wiley \& Sons.

Tuckman, B. W. (1965). Developmental sequence in small groups. Psychological Bulletin, 63(6), 384-399. doi:10.1037/h0022100 PMID:14314073

Ulrich, K. T., \& Eppinger, S. D. (2000). Product Design and Development. The McGraw-Hill Companies, Inc.

Vanhala, M., \& Ahteela, R. (2011). The effect of HRM practices on impersonal organizational trust. Management Research Review, 34(8), 869-888. doi:10.1108/01409171111152493

Vittal, S., Anantatmula, V. S., \& Kanungo, S. (2010). Modeling enablers for succesful KM implementation. Journal of Knowledge Management, 14(1), 100-113. doi:10.1108/13673271011015598

Wang, Y., \& Haggerty, N. (2009). Knowledge transfer in virtual settings: The role of individual virtual competency. Information Systems Journal, 19(6), 571-593. doi:10.1111/j.1365-2575.2008.00318.x

Yin, R. K. (2009). Case study research: Design and methods (4th ed.). California: Sage Publications.

Zigurs, I. (2003). Leadership in virtual teams: Oxymoron or opportunity? Organizational Dynamics, 31(4),339-351. doi:10.1016/S0090-2616(02)001328 
Päivi Lohikoski is a doctoral student of Industrial Engineering and Management at the Faculty of Technology at the University of Oulu. Her research interests are in knowledge management in virtual organizations and project communications. She received her MA degree in Information Studies from the University of Oulu, where she has worked as a University Lecturer and University Teacher since 2005. Her work experience has been concentrated on planning and teaching in e-learning projects and in addition she has several years work experience in the ICT industry in communication and documentation functions in $R \& D$.

Jaakko Kujala is a professor of project and quality management at the Department of industrial Engineering and Management at the University of Oulu, Finland. He has over ten years' experience in industry, while working in international automation system project business before his career in the academia. He has initiated and served as a director for several large research projects with the participation of leading project-based firms, such as Nokia Siemens Networks, Kone, Wärtsilä, Metso, and Outotec. His publications include more than 100 academic papers, book chapters and books on project business and on the management of project-based firms. His current research interests include contextual variables in project-based firms and project networks, business models in project-based firms, simulation and stakeholder management in the project business context.

Janne Harkonen received his bachelor's degree (1st Class Honours) in Engineering Business Management from University of Greenwich in the UK and both his M.Sc. in Process Engineering and Dr (Tech) in Industrial Engineering and Management, from the University of Oulu, Finland. He has also studied in the University of North Carolina at Wilmington, USA. He has worked for several years in the IT and environmental technology industries, in the UK and in Finland. Currently, he is a senior research fellow at the University of Oulu. Dr Harkonen has authored and co-authored over thirty journal articles, and also a number of other publications.

Harri Haapasalo is a professor in industrial engineering and management (IEM), University of Oulu, Finland. He holds a Doctor degree in IEM. His research interests cover Product management, value stream analysis and business models. He has authored and co-produced over 250 international articles.

Matti Muhos is research Director at the Oulu Southern Institute at University of Oulu. He holds a Doctorate in industrial engineering and management. He acts as an associate editor, quest editor and advisory board member of several international journals. His primary research interests include growth and internationalization of technology-intensive SMEs, configurations and management viewpoints, micro and SME entrepreneurship, agility and technology management. 


\section{APPENDIX 1}

Table 5. Virtual communication survey results

\begin{tabular}{|c|c|c|c|c|}
\hline Statement & $\begin{array}{l}\text { Disagree } \\
\%\end{array}$ & $\begin{array}{c}\text { Partly } \\
\text { disagree } \\
\%\end{array}$ & $\begin{array}{c}\text { Partly } \\
\text { agree } \\
\%\end{array}$ & $\underset{\%}{\text { Agree }}$ \\
\hline $\begin{array}{l}\text { My ICT (Information and Communication Technology)-skills } \\
\text { are sufficient for working in virtual teams. }\end{array}$ & 1 & 5 & 26 & 67 \\
\hline I have good communication skills in virtual environment. & 0 & 11 & 41 & 48 \\
\hline $\begin{array}{l}\text { It is not a problem that I can't see facial expressions and } \\
\text { gestures in virtual meetings. }\end{array}$ & 9 & 30 & 41 & 21 \\
\hline $\begin{array}{l}\text { Transferring advanced professional knowledge via ICT is not a } \\
\text { problem. }\end{array}$ & 11 & 29 & 43 & 18 \\
\hline ICT tools support and make my work easier. & 2 & 19 & 47 & 32 \\
\hline Virtual work environment enhances my job satisfaction & 11 & 41 & 38 & 10 \\
\hline Managers perform efficiently in virtual meetings. & 7 & 32 & 47 & 14 \\
\hline
\end{tabular}




\section{APPENDIX 2}

Figure 5.

\begin{tabular}{|c|c|c|}
\hline & \multicolumn{1}{|c|}{ Age of the informants } \\
\hline
\end{tabular}

